\title{
Sobre alguns dilemas da teoria neorrepublicana da liberdade
}

On some dilemmas of the neo-republican theory of freedom

Nos últimos anos, a chamada tradição republicana tem sido invocada como forma de enriquecer os debates contemporâneos em torno da liberdade, da cidadania e da democracia nas condições das sociedades plurais atuais. De maneira geral, este esforço de resgate histórico e reconstrução conceitual efetuou-se num contexto de insatisfação com os rumos das democracias e das sociedades liberais contemporâneas, sob fogo cerrado das dimensões mercantis e privatistas da vida. O retorno ao republicanismo apareceria, assim, como um grande esforço analítico de recuperação de uma linguagem e de uma prática da vida pública soterrada pela hegemonia do pensamento político liberal.

No entanto, ao se mostrar como possibilidade de reflexão política alternativa ao liberalismo, o chamado neorrepublicanismo contemporâneo tem sido colocado diante de questões de difícil resolução suscitadas exatamente pela complexidade dos temas com os quais pretende lidar e pela reação liberal desencadeada em suas versões filosóficas mais sofisticadas. Neste trabalho, destacamos duas críticas liberais ao neorrepublicanismo de Skinner (1999) e Pettit (1997) : em primeiro lugar, a questão de que estes autores não caracterizariam corretamente o liberalismo como forma de

1 Professor Adjunto do Departamento de Ciências Humanas da Universidade Federal de Alfenas (MG), rua Gabriel Monteiro da Silva 700, Alfenas, MG, Brasil. E-mail: gleytontrindade@hotmail.com

2 Professor Associado do Departamento de Ciência Política da Universidade Federal de Minas Gerais, Av. Antônio Carlos 6627.Belo Horizonte, MG, Brasil. E-mail: juarezrg15@gmail.com 
contrapô-lo ao republicanismo e, em segundo lugar, a crítica liberal de que, ao tomar as virtudes públicas de maneira instrumental, o neorrepublicanismo não se constituiria como tradição política alternativa ao liberalismo, mas, ao contrário, poderia ser compatibilizado com o próprio liberalismo.

Nossa tentativa de resposta a estas duas críticas liberais procura reconhecer os avanços analíticos de constituição de um conceito de liberdade alternativo ao liberal na obra destes dois neorrepublicanos contemporâneos, mas apontará em que medida podem ser notados os limites deste empreendimento. Neste sentido, sustentaremos a ideia de que, embora Skinner e Pettit tenham contribuído decisivamente ao procurar atribuir, histórica e filosoficamente, estatuto próprio à tradição da liberdade republicana, restituindo o valor da vida pública em relação às versões mais privatistas do liberalismo, ainda resta insuficiente a análise de elementos que podem tornar a concepção republicana de liberdade mais claramente alternativa à liberal. Pettit e Skinner não desenvolveriam uma análise da liberdade republicana associada à uma "gramática" republicana, no sentido de que pensariam a liberdade desarticulada de uma linguagem de direitos e deveres que configuram as relações entre público e privado a partir da lógica do próprio lugar da política.

Diferentemente, tratar-se-ia de pensar o momento de fundação política como organizador de valores que constituem a vida coletiva e articulam noções de bem e de justiça. Relacionado ao anterior, um segundo limite da elaboração conceitual destes autores estaria em tomar certas virtudes e ideais da vida pública de maneira puramente instrumental, sem reconhecer que certos valores têm importância intrínseca à liberdade republicana. Assim procedendo, assumiriam o postulado liberal da neutralidade de fins, reforçando o dogma de que, como aponta Spitz, os homens que romperam com os postulados da ética aristotélica não podem compartilhar nenhuma concepção do bem (Spitz, 1995a, p. 172). Retomar estas questões nos parece fundamental para repensar o próprio sentido da liberdade republicana. 


\section{Neorrepublicanismo e liberdade}

Em grande medida, o resgate da tradição republicana empreendido por Skinner (1999) e Pettit (1997) se deu em função do debate sobre a concepção de liberdade que deveria governar a vida pública. A partir da concepção dicotômica dos conceitos de "liberdade positiva" em oposição à "liberdade negativa", expressa por Benjamin Constant na oposição entre liberdade dos antigos e dos modernos, atualizada, entre outros, por Isaiah Berlin (2002), o pensamento político contemporâneo havia fixado a ideia de que este último conceito seria a única alternativa para compreender as condições em que se realiza a relação dos indivíduos com a esfera pública na modernidade. No caso de Berlin, trata-se, mais uma vez, da defesa de uma concepção liberal da liberdade entendida como "ausência de impedimento" e centrada nos direitos dos indivíduos contra qualquer concepção de liberdade pensada em relação à filiação do indivíduo a uma comunidade política. Na verdade, a intenção seria exatamente denunciar o perigo de uma noção de liberdade tributária de um ideal de "bem comum" a partir do qual uma coletividade possa se colocar acima das vontades individuais, não reconhecendo a pluralidade da sociedade moderna. Desfazendo a ilusão do apelo antigo a ideais comunitários e unificadores no contexto das sociedades atuais, o liberalismo de Berlin buscaria pensar a liberdade com a justificativa de salvaguardar o indivíduo de possíveis intromissões da ordem política entendida como campo externo à própria liberdade.

O significado da liberdade como ausência de impedimento à ação individual denotaria a ideia de que um agente livre é aquele que pode, se assim o desejar, mover-se dentro de sua área de atuação sem sofrer constrangimento ou a interferência deliberada de outros seres humanos (Berlin, 2002, p. 229). No caso, o impedimento provém sempre de uma fonte externa ao indivíduo, de tal forma que ele não pode reclamar ser coagido por si mesmo ou manifestar a falta de liberdade para aquilo que é realmente incapaz de realizar. Ainda mais, a interferência do outro pode se dar para impedir o agente de realizar o que deseja ou para obrigar-lhe a realizar aquilo 
que não deseja. Outro aspecto importante desta caracterização da liberdade negativa é que a noção de interferência a ela associada se refere a uma situação de coação efetiva e não a uma situação em que há a possibilidade de coação, ou seja, até que a coerção não ocorra, o indivíduo é alguém considerado como portador de liberdade que será tanto maior quanto maior for a área de não interferência na sua área de atuação (Berlin, 2002, p. 231). Desta maneira, Berlin (2002) conceberia a lei como uma clara interferência externa na área em que o indivíduo deve ser livre para agir conforme deseja. Desta forma, toda lei, por mais que seja legítima, implicaria em alguma restrição da liberdade. Em certa medida, isto seria justo e necessário uma vez que a liberdade não é o único valor relevante aos seres humanos e, portanto, com certos limites, torna-se necessária a elaboração de leis que limitem a liberdade em função do benefício de outros valores.

Não é gratuito, portanto, o fato de Skinner, aquele considerado um dos grandes expoentes do republicanismo contemporâneo, mostrar-se insatisfeito com a ênfase liberal nos direitos individuais em suas reflexões sobre o republicanismo de Maquiavel (Silva, 2008, p. 165; Pettit, 2002, p. 340). Em seus primeiros escritos sobre a temática da liberdade, Skinner já expressava seu descontentamento com a ênfase da teoria política contemporânea na primazia dos direitos em detrimento dos deveres dos cidadãos como meio de manutenção da ordem republicana. Neste itinerário em busca de uma outra concepção de liberdade que agregasse a importância dos deveres cívicos, um primeiro passo estaria em contraditar o esquematismo da associação feita entre liberalismo e liberdade negativa em oposição a republicanismo e liberdade positiva. Neste sentido, em um primeiro momento, Skinner apontaria para uma maior complexidade desta identificação ao procurar demonstrar que alguns autores republicanos haviam argumentado em favor de uma concepção negativa de liberdade entendida como não coerção, diferentemente do que era de se esperar. O que distinguiria republicanos e liberais não seria, portanto, a concepção de liberdade negativa, mas a crença, entre os republicanos, de que esta liberdade 
negativa só poderia ser garantida pela virtude da incorporação e da participação dos cidadãos numa república política, ou seja, num Estado livre (Pettit, 2002, p. 340). Por influência da obra de Pettit (1997), Skinner passou a reconhecer que a tradição neorromana e o liberalismo discordavam a respeito do próprio conceito de liberdade, e não apenas em relação às condições da liberdade, embora as duas tradições políticas pudessem ser reconhecidas como vinculadas à concepção de liberdade negativa (Skinner, 1999, p. 62). Além da noção de não coerção, existiria uma tradição política que acrescentaria á noção de não dependência ao conceito de liberdade. Esta questão se reveste de significado importante para se compreender o próprio sentido do esforço de retomada republicana empreendido por Skinner e Pettit. Não se trata de simplesmente negar a existência de um republicanismo adepto de uma noção de liberdade positiva, mas de demonstrar que esta tradição política é mais plural do que parece supor liberais como Berlin. Skinner (1999) expressaria esta questão realizando uma diferenciação entre as tradições políticas neoateniense e neorromana, identificando as divergências entre o que Palonen (1999) denominaria como visões "determinista" e "oportunista" da liberdade republicana e Honohan (2002) denominaria como "republicanismo forte" e "republicanismo instrumental".

Assim, o que se poderia classificar como republicanismo instrumental, do qual Pettit e Skinner seriam destacados representantes contemporâneos, seria aquele identificado com uma concepção de liberdade negativa em que a cidadania é concebida como um meio para se preservar a liberdade individual, antes que uma atividade ou relação que tenha um valor intrínseco. Já o republicanismo forte, identificado contemporaneamente com o chamado "comunitarismo" na filosofia política norte-americana e supostamente tributário de uma concepção de liberdade positiva, enfatizaria o valor inerente da participação no autogoverno e a realização de determinados 
bens comuns entre os cidadãos (Honohan, 2002, p. 9) 3 $^{3}$ Neste sentido, entre a concepção de liberdade negativa do liberalismo e a concepção de liberdade positiva do republicanismo forte, o neorrepublicanismo de Skinner e Pettit se colocaria como uma terceira via (Spitz, 1995b). A diferenciação entre as tradições neoatenienses e neorromanas, como estabelecida por Skinner (1999), implica o reconhecimento das diferentes fontes destes republicanismos. Ambos se inspiram no pensamento clássico antigo, mas, se por um lado, os neoatenienses se ancorariam nas instituições da politeia de Atenas e no pensamento político de Aristóteles, os neorromanos teriam como referência fundamental o constitucionalismo romano e seus principais intérpretes antigos nas figuras de Políbio, Tito Lívio, Sêneca e Cícero. A diferença fundamental entre estas duas formas de conceber a organização política estaria no reconhecimento da diversidade num contexto de cidadania inclusiva por parte dos romanos que não se verificaria nas experiências e no pensamento grego (Buttle, 2001). ${ }^{4}$

Em sua reconstrução histórica do conceito de liberdade, portanto, Skinner (1999) reconheceria na tradição neorromana uma concepção da liberdade compreendida, simultaneamente, como "não interferência", neste ponto em conformidade com os liberais, e como "não dependência". O reconhecimento de uma característica distintiva da concepção republicana de liberdade apareceu, como o próprio Skinner admite, da influência das reflexões desenvolvidas por Pettit (1997). Nas palavras de Pettit, "a afirmação na leitura de Skinner de que os republicanos se preocupavam com a dependência é claramente convergente com minha própria afirmação de que eles

3 Taylor, ele próprio frequentemente classificado como um pensador comunitarista, identifica sob esta denominação, na filosofia política norte americana, a obra de autores como Michael Sandel, Alasdair McIntyre e Michael Walzer. Ver Taylor, 2000a, p. 197). No entanto, a utilização de tal classificação não deixa de ser controversa e renegada por aqueles frequentemente apontados como comunitaristas. É o caso de Sandel (1996, p. 66).

4 A este respeito, Pettit (1997) aponta o elitismo como um dos problemas relacionados ao republicanismo clássico. Por isto mesmo, sua definição do neorepublicanismo incorpora a noção de uma cidadania inclusiva. Apesar disto, é interessante notar como autores contemporâneos como McCormick (2003) avaliam o neorepublicanismo de Pettit como democraticamente aquém do republicanismo de Maquiavel. 
se preocupavam com a dominação, e ele é generoso em reconhecer a conexão com meu trabalho" (Pettit, 2002, p. 341). Apesar desta convergência, Pettit solicitaria a Skinner uma "simplificação" do conceito de liberdade republicano, ou seja, um conceito que focalizasse a noção de "não dependência" como elemento específico do republicanismo em contraste com a noção de "não interferência” liberal (Pettit, 2002, p. 345). A preocupação central de Pettit a este respeito estava no vício liberal em conceber, através da noção de "não interferência", qualquer lei como elemento de limitação da liberdade. Tal solicitação seria depois atendida por Skinner (2006; 2007). Ainda mais recentemente, Skinner (2010) também aceitaria de Pettit a sugestão de se referir à tradição de pensamento vinculada à concepção neorromana de liberdade como "republicanismo" ao mesmo tempo em que faria notar uma reavaliação da origem e desenvolvimento do conceito de liberdade como não interferência na obra de Hobbes. ${ }^{5}$

Por sua vez, ao qualificar o que Skinner chamava de "não dependência” como "não dominação", Pettit, mais uma vez, apontava para a importância do fato de que na tradição republicana, "liberdade é sempre percebida nos termos da oposição entre líber e servis, cidadão e escravo" (Pettit, 1997, p. 8). Também mais uma vez, trata-se de um republicanismo que procura resgatar o conceito de liberdade da dicotomia liberdade negativa/liberdade positiva tornada dominante na teoria política contemporânea por Berlin. Entre estes dois polos, seria possível pensar numa possibilidade intermediária que "teria um elemento conceitual em comum com a concepção negativa - o foco na ausência, não na presença - e um elemento em comum com a positiva: o foco no domínio, não na interferência" (Pettit, 1997, p. 22). Esta concepção alternativa seria a concepção de liberdade como "não dominação" ou como "antipoder", representada na tradição do pensamento político pelo republicanismo de pensadores como Maquiavel. Desta forma, "a condição de liberdade é explicada como

5 É preciso notar, no entanto, que a aceitação do termo republicanismo parece ocorrer à contragosto do próprio Skinner como decorrência do reconhecimento de sua derrota a respeito da validade de tal termo no debate histórico contemporâneo. Ver Skinner (2010, p. 9). 
o status de alguém que, diferentemente do escravo, não está sujeito ao poder arbitrário de outro, ou seja, alguém que não é dominado por nenhum outro" (Pettit, 1997, p. 31).

O ideal de liberdade como "não interferência" sofreria, portanto, de dois limites principais. O primeiro seria o de, ao colocar a interferência como afronta principal à liberdade, não realizar a distinção entre interferência arbitrária e não arbitrária. Trata-se da distinção entre a interferência que é forçada a reconhecer os interesses de quem a sofre e, por outro lado, um tipo de interferência hostil, que não é forçado a reconhecer os interesses de quem a sofre, refletindo apenas os interesses de quem a causa. "O primeiro tipo de interferência é não arbitrário, no sentido de que ela é controlada, de uma forma passiva ou virtual, por meio do que, quem sofre a interferência, pensa ou quer. O segundo tipo é arbitrário, no sentido de que falta tal controle (...)" (Pettit, 2007, p. 186). Ao não realizar tal distinção, o ideal de não interferência seria levado a afirmar que todas as formas de elaboração de leis e da administração pública são limitações, como tais, da liberdade política. Neste sentido, a concepção da liberdade como não interferência seria pobre constitucionalmente para reconhecer as diferentes formas em que um Estado pode se organizar. Ela não conseguiria captar os contrastes que existem entre Estados que diferem no grau de arbitrariedade que as autoridades têm sobre os cidadãos. Neste sentido, a única preocupação do liberalismo adepto desta concepção passaria a ser seu interesse em limitar a interferência do Estado, minimizando como um todo o grau de interferência das agências públicas e privadas.

Além de não ser capaz de reconhecer os diferentes tipos de Estado e o grau de arbitrariedade que eles podem impor aos cidadãos, o ideal de não interferência também não seria capaz de compreender a diferença da interferência do Estado em relação à interferência de outras formas de agência privada. Neste aspecto, ele não apontaria para a grande diferença entre o poder relativamente não arbitrário através do qual o Estado, sob a lei e o direito, pode impor aos cidadãos impostos e punições a crimes e o poder absolutamente arbitrário que um indivíduo ou uma corporação assume 
quando coagem ou manipulam outros indivíduos em benefício próprio. Pettit aponta para o absurdo desta falta de reconhecimento ao anotar que, se a interferência de uma agência pública sobre indivíduos se verifica mediante o reconhecimento dos próprios interesses assumidos por estes indivíduos, "nessa medida, não importa quão limitada ela seja, a interferência exercida não desafia a possessão do controle discursivo do indivíduo, da mesma forma que o faz a interferência dos criminosos comuns" (Pettit, 2007, p. 187). ${ }^{6}$ Ao apontar a interferência como a primeira afronta à liberdade, a concepção liberal de liberdade interditaria, ou pelo menos tornaria de difícil justificativa, importantes ações do Estado no sentido de eliminar limitações dos cidadãos associadas à deficiência, pobreza e situações de desigualdade e assimetrias de poder. Na medida em que toda ação do Estado envolve interferência e toda interferência é compreendida como limitação da liberdade, torna-se prejudicada a justificação de um Estado de bem-estar redistributivo que possa embasar a busca da autonomia dos cidadãos.

Uma segunda crítica ao ideal de não interferência seria a de que, além dele se mostrar constitucionalmente fraco, também seria sociologicamente insuficiente ao não ser capaz de identificar todas as situações sociais em que os indivíduos estariam expostos à perda da liberdade. $\mathrm{O}$ problema aqui seria a sugestão liberal de que somente uma interferência pode subtrair liberdade e, portanto, não haveria problema em situações em que a interferência não se efetiva, embora o indivíduo seja colocado em situação de dependência da vontade arbitrária de outro. O exemplo paradigmático desta situação é a do escravo submetido a um mestre benevolente. Nesta situação, a concepção de liberdade como não interferência não

6 É interessante notar como Pettit se aproxima das reflexões de Hannah Arendt a este respeito. Numa crítica á uma determinada concepção liberal do poder, Arendt se refere ao erro de se conceber poder como sinônimo de violência, o erro, portanto, de fazer crer que a ação de um criminoso sobre sua vítima é da mesma natureza que a ação das instituições públicas sobre os cidadãos. Ver Arendt (1998). 
identificaria aí nenhum tipo de afronta à liberdade. ${ }^{7}$ Neste contexto, o ideal republicano de liberdade como "não dominação" se mostraria duplamente vantajoso. Em primeiro lugar, assim entendida, não se denunciaria todo tipo de interferência como limitação da liberdade, mas tão somente o tipo de interferência arbitrária. Desta forma, leis publicamente discutidas e estabelecidas "criam a autoridade de que desfrutam os legisladores, elas também criam a liberdade que os cidadãos compartilham" (Pettit, 1997, p. 36). Já que a liberdade se constitui como um status reconhecido publicamente, torna- se necessário que ela seja garantida institucionalmente de tal forma que as leis se coloquem como elemento limitador da arbitrariedade.

Em segundo lugar, a concepção de liberdade como não dominação seria sociologicamente mais rica porque ela reconhece que um indivíduo pode ser colocado em situação de dominação mesmo que não esteja exposto à uma condição de interferência direta. Nesta concepção, um indivíduo é considerado como dominado na medida em que, mesmo que não sofra interferência, esteja exposto à possibilidade da interferência arbitrária de outro. Portanto, não é livre aquele cidadão que vive sob condição de dependência. Nesta situação, afirma Pettit, o preço da liberdade não é a eterna vigilância, mas a eterna discrição, uma vez que a possibilidade de censura e punição arbitrária já seria o suficiente para alterar e inibir o comportamento do indivíduo. Desta forma, longe de entender a ação do poder público como um inimigo da liberdade, ele cumpriria um papel fundamental de resolver aqueles problemas que surgem do fato de que existem poderes assimétricos de interferência.

É verdade que intérpretes contemporâneos de Berlin têm realizado reparos a avaliação feita pelos teóricos neorrepublicanos de sua teoria da liberdade como não interferência (Gray, 2000; Coser, 2014).

7 Pettit identifica várias situações em que pode se aplicar a mesma reflexão."Pensemos no filho de um pai emocionalmente instável, a mulher do marido ocasionalmente violento ou o aluno de um professor que decide, de forma arbitrária, de quem gosta e de quem não gosta. Pensemos no empregado cuja segurança requer que ele mantenha o chefe ou o gerente feliz, o devedor cujas chances dependem do humor variável de quem empresta o dinheiro (...). Em todos esses casos cada um vive à mercê dos outros. A pessoa é dominada pelos outros no sentido de que, mesmo que os outros não interfiram na sua vida, eles têm o poder arbitrário de fazê-lo". (Pettit, 2007, p. 189 e 190). 
Em especial, tais intérpretes têm negado a ideia de que o liberalismo berliniano desconheceria a distinção entre intervenção arbitrária e interferência legítima visando corrigir situações de opressão. Para Coser (2014), por exemplo, a oposição entre liberdade positiva e liberdade negativa não seria o foco central da teorização berliniana. O eixo organizador do conceito de liberdade berliniano estaria assentado na ideia da liberdade de escolha que pressupõe, primeiro, a autonomia do agente que possui a capacidade de fazer escolhas e pode fazer livre uso dessa capacidade e, em segundo lugar, a ideia de que os sujeitos visam buscar seus próprios objetivos sem serem forçados a buscar um fim específico. Dessa forma, seria incorreto atribuir a Berlin uma concepção de que somente uma intervenção efetiva significaria um constrangimento a liberdade. Na visão berliniana da liberdade os cidadãos estariam numa situação de dominação opressiva quando acomodam suas escolhas e seus desejos a um campo estreito de possibilidades em função de constrangimentos externos mesmo que essa dominação se exerça sem efetiva intervenção. Bastaria, para tanto, que os sujeitos se submetam a vontade discricionária de outro (Coser, 2014, p. 46). Nesse mesmo sentido, diferentemente do que afirmaria Pettit, Berlin conceberia a necessidade da intervenção da lei como instrumento para assegurar a liberdade de escolha, para garantir certos direitos e para prevenir situações de opressão. Desta forma, o conceito berliniano de liberdade requereria algum grau de intervenção pública sem a qual os cidadãos não teriam garantida uma esfera para realização de escolhas livres.

Ainda assim, faltaria a Berlin a noção neorrepublicana de que a liberdade requer princípios de bem comum que pressupõem uma dimensão comunicativa, ou seja, não somente a proteção contra formas de poder arbitrário, mas também que os cidadãos sejam capazes de estabelecer diálogos e ações em comum (Coser, 2014, p. 62). Em nossa concepção, se a liberdade republicana deseja ser alternativa a liberdade liberal, essa dimensão comunicativa deve ser enfatizada para além do que afirmam Skinner e Pettit através do reconhecimento de que determinados valores republicanos são 
intrínsecos à liberdade como não dominação e por uma concepção do político como origem do social e da própria condição da liberdade.

\section{Duas críticas liberais}

O neorrepublicanismo de Pettit tem o mérito de romper com o esquematismo da simples oposição entre liberdade positiva contra liberdade negativa, além de se inserir no debate contemporâneo sobre a democracia a partir de termos diferentes dos quais tal debate é normalmente organizado. No entanto, resta-nos a questão decisiva de avaliar em que medida o empreendimento neorrepublicano foi capaz de superar os limites do liberalismo. De fato, é possível reconhecer que a proposta institucional da "democracia contestatória", como proposta por Pettit, resulta num arranjo que não é estranho à tradição liberal. Neste sentido, a própria crítica republicana tem chamado atenção para o fato de que a reflexão democrática de Pettit e as ações institucionais que decorrem desta proposta podem ser facilmente compatibilizadas com o próprio liberalismo (Bignotto, 2004; McCormick, 2003) ${ }^{8}$. Nestes termos, a crítica poderia incidir, por exemplo, na crença de que se poderia expandir e enriquecer o quadro dos direitos públicos e da igualdade abrindo mão de se pensar também formas de democratização da vida política e de uma renovada cultura de participação entre os cidadãos. Em outros termos, poder-se-ia apontar a contradição de se propor um alargamento dos direitos públicos sem uma correspondente expansão qualitativa da vida política ativa por parte dos cidadãos.

Em outro sentido, a crítica liberal tem procurado atacar os próprios fundamentos conceituais a partir dos quais se constituiu a concepção republicana de liberdade. Para nossos propósitos, a análise desta reação liberal se reveste de significativa importância na medida em que ela procura inviabilizar a concepção republicana

8 McCormick, em especial, acusa o neorepublicanismo de Pettit de subestimar os elementos democráticos da teoria política de Maquiavel. O resultado, seria um certo aristocratismo por parte de Pettit que não encontraria correspondente na obra maquiaveliana. Ver McCormick (2003). 
de liberdade e a própria tradição republicana como alternativa de reflexão política ao liberalismo.

Poder-se-iam destacar dois tipos destas críticas. O primeiro seria aquele formado pelas reflexões que contestam a forma como os pensadores neorrepublicanos têm descrito a tradição liberal com a qual pretendem dialogar criticamente (Larmore, 1999; Larmore, 2001; Larmore, 2003; Mitchell, 2004; Rogers, 2008). Nesta perspectiva, o republicanismo contemporâneo teria falhado ao não reconhecer a pluralidade da tradição liberal, acarretando a crítica a um tipo específico de liberalismo a partir do qual se construiriam bases frágeis para realizar a distinção entre as tradições liberais e republicanas. Um segundo tipo de crítica seria aquele que busca bloquear o projeto neorrepublicano por identificar em seu interior elementos afins ao próprio projeto liberal (Rawls, 1996; Patten, 1996; Kymlicka, 1998). Na verdade, na concepção destes críticos, as divergências entre liberais e republicanos seriam pouco significativas uma vez que ambas as abordagens afirmariam a neutralidade de valores da organização política e o caráter instrumental de certos ideais e virtudes, com o objetivo de fortalecer um sistema de proteção aos indivíduos.

A primeira crítica liberal centra-se na oposição estabelecida por Pettit entre a concepção republicana de liberdade e a tradição moderna liberal, compreendida como aquela que teria uniformemente aderido ao ideal de liberdade como não interferência. Esta linha de argumentação incorreria no erro de conceber a tradição liberal como monoliticamente associada a este ideal (Larmore, 2003, p. 234). Aqui, não se trata de negar a existência de uma importante corrente liberal vinculada ao ideal de liberdade como não interferência. De fato, um modelo de sociedade aberta pensada a partir da noção de liberdade como ausência de interferência foi expresso por Bentham e inspirou importantes correntes do pensamento liberal. No século XIX, Stuart Mill assumiria tal concepção ao relacionar a liberdade à "perseguição de seu próprio bem seguindo seu próprio caminho" e ao conceber a lei como sua restrição. Tal concepção encontraria notável acolhida entre liberais já no século 
XX. O problema colocado para os neorrepublicanos seria pensar que o liberalismo como um todo coincidiria com esta linha de pensamento. Esta dificuldade apareceria já na compreensão de Locke, aquele que poderia ser considerado um dos pais fundadores do liberalismo. Locke claramente não definiria liberdade como ausência de interferência e insistiria no papel da lei como elemento constituidor da própria liberdade. ${ }^{9}$ Mas não apenas em Locke poderia ser identificada esta perspectiva. Também Benjamin Constant em sua famosa evocação da liberdade dos modernos indicaria que esta consistiria na sujeição à lei em oposição à sujeição à vontade arbitrária de outro e de que tal arbitrariedade não se referiria meramente à interferência atual, mas à própria possibilidade da ocorrência de tal interferência (Larmore, 2003) ${ }^{10}$. Neste sentido, o liberalismo constituiria uma tradição política plural, podendo tanto ser identificada com o ideal de liberdade como ausência de interferência, isto mais explicitamente em relação ao pensamento utilitarista, quanto com uma grande gama de pensadores que rejeitariam uma oposição essencial entre lei e liberdade.

Ainda em relação à caracterização do liberalismo, a teoria neorrepublicana incorreria num erro ainda mais importante. Ela não teria sido capaz de reconhecer a complexidade da própria concepção de liberdade negativa no liberalismo ao estender uma linha de continuidade entre Hobbes e a própria tradição liberal (Mitchell, 2004; Rogers, 2008). Tal erro poderia ser observado na argumentação de Pettit a respeito da adesão de Rawls à concepção de liberdade negativa. Pettit observa, com razão, que Rawls manifesta uma concepção de liberdade como não interferência ao afirmar

9 A reação liberal, com frequência cita o texto de Locke como demonstração da insuficiência caracterização do liberalismo como liberdade como não interferência. O texto de Locke afirma que "a lei, no seu verdadeiro significado, é não só a limitação, mas a direção de agente livre e inteligente para o seu próprio interesse e não prescreve mais do que importa no bem geral de quantos estão sob esta lei. (...) o objetivo da lei não consiste em abolir ou restringir, mas em preservar e ampliar a liberdade". Ver Larmore (2001, p. 235). Sem resposta para esta questão, Pettit o inclui como pensador republicano.

10 Em relação à Benjamin Constant, Larmore (2001, p. 236) cita a passagem do pensador francês segundo o qual a liberdade "é o direito de ser sujeito apenas às leis, de tal forma que ninguém possa ser preso, detido, executado ou maltratado em virtude da vontade arbitrária de um ou de muitos indivíduos". 
a necessidade de leis restritivas apenas na medida em que se trata de salvaguardar a existência da própria liberdade. $\mathrm{O}$ problema seria derivar daí uma continuidade entre Hobbes e o liberalismo de Rawls sem compreender toda a complexidade envolvida na concepção de liberdade liberal deste último. $\mathrm{Na}$ crítica neorrepublicana estaria obscurecido o fato de que a concepção negativa de liberdade liberal seria composta na verdade por dois elementos: um descritivo e um normativo (Rogers, 2008, p. 805).

$\mathrm{O}$ elemento descritivo seria aquele identificado pelos próprios neorrepublicanos, ou seja, a concepção de liberdade como ausência de impedimentos externos derivado da obra de Hobbes. Neste aspecto, de fato, a liberdade negativa seria compatível com diversas formas de dominação desde que a soberania absoluta não interfira diretamente na área de ação humana. Neste elemento descritivo, portanto, a liberdade negativa se refere meramente à descrição das oportunidades de ação humana e às situações de imposição de obstáculos a elas. O elemento normativo da concepção de liberdade negativa diferenciaria o pensamento liberal de um Rawls em relação ao de Hobbes. A liberdade não consistiria meramente na propriedade de um indivíduo isolado ao qual se pode estender ou limitar o campo de ação, como pensado por este último, mas diria respeito às próprias características de uma forma de vida social e política. Neste sentido, a concepção de liberdade liberal estaria vinculada a uma condição de segurança psicológica e independência pessoal, imparcialidade legal com um sistema de leis aplicado igualmente para todos e auto regulação coletiva através de eleições e livre discussão. Assim, aquilo que o liberalismo demandaria normativamente para assegurar a liberdade o distinguiria da concepção de liberdade negativa hobbesiana (Rogers, 2008, p. 806). Desta forma, a liberdade liberal significaria menos do que ser livre de todo e qualquer constrangimento, mas também significaria mais do que estar livre apenas da interferência direta, no sentido de que o liberalismo também estaria atento às condições em que há a possibilidade de sujeição. Neste sentido, para além do fato do liberalismo constituir uma tradição política plural, contando 
inclusive com defensores de uma concepção de liberdade próxima à concepção de não dominação, sua definição da liberdade política deveria ser compreendida num quadro mais amplo de delimitação da própria concepção liberal da vida em sociedade e das condições de organização da vida política (Waldron, 1987; Rogers, 2008).

Esta questão nos conduz a um segundo conjunto de críticas liberais ao neorrepublicanismo contemporâneo. Trata-se daqueles críticos que, a despeito de reconhecerem algumas diferenças entre liberais e republicanos, argumentam não existir divergências significativas entre as versões contemporâneas destas tradições na medida em que ambas compartilham de uma concepção instrumental de certos ideais e virtudes que tenham como efeito a manutenção de um sistema de liberdade para os indivíduos (Rawls, 2000; Patten, 1996; Kymlicka, 1998). Para estes críticos, os republicanos acompanham os liberais ao ignorar valores de cidadania e virtude cívica como intrínsecos à liberdade e ao não atribuir importância significativa à promoção destes ideais. Desta maneira, teóricos neorrepublicanos estariam incorretos ao argumentar que cidadania e serviços públicos constituiriam bens ao contribuírem para a realização da liberdade negativa porque, na verdade, a chave para compreender a relação entre liberalismo e neorrepublicanismo contemporâneo estaria no fato de que ambas as tradições têm uma visão instrumental das instituiçõos políticas e de valores públicos concebidos como meios para o fim das liberdades individuais (Patten, 1996, p. 25).

De fato, como já o notamos, o neorrepublicanismo de figuras como Pettit identificaram-se com um projeto de reflexão sobre a liberdade alternativo àquele que buscaria fins comunitários considerado incompatível com a pluralidade de valores das sociedades contemporâneas. Esta preocupação com a concepção de uma ordem política neutra em relação aos fins aos quais os indivíduos se destinam como forma de garantir o pluralismo conduziria Pettit a "busca de um argumento relativamente neutro para o Estado um argumento que não seja preso a nenhuma concepção particular do bem (...)". No contexto do debate entre liberais e comunitaristas a respeito dos valores políticos, Pettit afirmaria mesmo que 
"o republicanismo se une ao liberalismo contra o comunitarismo" na perspectiva de negar a validade de valores últimos (Pettit, 1997, p. 120). Assim, se o liberalismo se posicionaria a partir de uma "neutralidade de valores", o republicanismo se posicionaria a partir do que se poderia designar como "neutralidade de valores compartilhada" (shared-value neutralism), no sentido de que a liberdade como não dominação conduziria os próprios cidadãos a universalizar e tomar a neutralidade de valores como um bem importante a ser promovido e garantido pela ação política coletiva (Pettit, 1998, p. 90 e 91). Esta aproximação permitiria à crítica liberal negar a existência de diferenças significativas entre o liberalismo e o neorrepublicanismo contemporâneo.

Sobre este tema, a grande referência liberal contemporânea é, mais uma vez, a obra de Rawls (2000). Como o próprio Rawls reconheceria, o ideal de uma comunidade política seria abandonado porque considerada incompatível com o fato do pluralismo razoável, ou seja, "ela não é mais uma possibilidade política para aqueles que aceitam as restrições impostas pela liberdade e pela tolerância que são próprias de instituições democráticas" (Rawls, 2000, p. 250). Assim, entre o liberalismo político e o republicanismo, "não há uma oposição fundamental, porque o republicanismo clássico não pressupõe uma doutrina religiosa, filosófica ou moral abrangente. Nada no republicanismo clássico é incompatível com o liberalismo como o descrevi" (Rawls, 2000, p. 254). Situação diferente ocorreria em relação às formas de republicanismo que assumiriam dimensões aristotélicas afirmando a participação política como o lugar da vida digna porque isto significaria retornar ao campo das doutrinas abrangentes e seus perigos ao pluralismo ${ }^{11}$.

\section{Uma tentativa de resposta}

Se, por um lado, seria injusto acusar Pettit de não reconhecer importantes diferenças internas à tradição liberal, por outro,

11 Como representante da dimensão aristotélica da vida política, Rawls pensa especialmente em Arendt (2008). Entre as obras do revival republicano, o trabalho já clássico de Pocock (1975) normalmente é apontado como neoaristotélico. 
deve-se reconhecer a insuficiência de sua crítica à liberdade como não interferência como forma de alcançar uma crítica válida para o liberalismo como um todo. ${ }^{12}$ A razão desta insuficiência deve ser entendida a partir da necessidade do próprio republicanismo contemporâneo estabelecer uma relação apropriada com aquilo que poderíamos chamar de uma "gramática", ou seja, o modo de conceber a articulação entre o mundo público e privado, e o conceito de liberdade como sua matriz de significado. Por não ter sido capaz de articular um conceito de liberdade a uma gramática mais englobante, a análise neorrepublicana centrou-se na discussão da liberdade como formada por diferentes instâncias relativamente autônomas, nas formas das liberdades econômica, religiosa, política, de expressão.

Diferentemente, seria necessário pensar a liberdade a partir de um conceito mutuamente configurado, englobando aquelas várias dimensões da liberdade. Pensar desta forma significaria afirmar que o conceito de liberdade se organiza em relação a um conjunto de conceitos afins que articulam toda uma gramática política. Desta maneira, diferentes conceitos de liberdade articulam diferentes concepções da passagem da dimensão do indivíduo para a da comunidade política, das esferas subjetivas para as esferas comunitárias, da política até as diferentes dimensões da vida em sociedade. Neste aspecto, trata-se de afirmar o caráter instituinte da dimensão ético-política no sentido de que o espaço da política é pensado como o lugar da liberdade para além das determinações e teleologias extrínsecas à própria política. Desta forma, o caráter instituidor da dimensão ético-política se relacionaria à afirmação de uma determinada gramática que articula as dimensões sociais e econômicas de uma sociedade aos princípios que orientam a organização dos fundamentos do Estado que amparam os acordos sociais em torno do reconhecimento de um conjunto de direitos e

12 De fato, embora Pettit identifique no liberalismo a concepção de liberdade como não interferência, ele próprio admite a diferença entre um liberalismo que toma o componente formal da não interferência como ideal supremo relevante e um outro liberalismo que combina o ideal com a igualdade ou a erradicação da pobreza para constituir o supremo ideal político. Ver Pettit (2007, p. 185). 
deveres formadores das instituições políticas e da vida econômica e social. Em outros termos, seria necessário reconhecer a dimensão do "político" como descrito por Lefort (1991). Nas palavras de Rosanvallon, "o político pode, portanto, ser definido como o processo que permite a constituição de uma ordem a que todos se associam, mediante deliberação das normas de participação e distribuição" (Rosanvallon, 2010, p. 42).

Com isto, não queremos sugerir que autores como Skinner e Pettit tenham deixado de lado a importância da dimensão pública da vida e das virtudes públicas. Trata-se, muito mais, de apontar a necessidade de aprofundar ainda mais essa dimensão da teoria neorrepublicana da liberdade como forma de fazer frente aos desafios lançados pela teoria liberal. É certo que Skinner (1991) nega explicitamente a noção liberal de que o melhor para todos surge da busca do auto interesse uma vez garantidos os direitos individuais. Diferentemente, a própria liberdade do indivíduo é pensada em relação a importância do cultivo das virtudes públicas e do cumprimento de seus deveres para com a república. Skinner se aproxima da noção do "político" ao tomar a metáfora do corpo político como "corpo orgânico", ao discutir sobre o significado republicano da vida em um estado livre e ao afirmar que este estado celebra constitucionalmente suas virtudes. No entanto, também assinala, como justificativa para a defesa do Estado livre, a versão instrumental segundo a qual uma das principais vantagens deste em relação a estados não livres é permitir que os cidadãos busquem seus próprios fins (Skinner, 1991, p. 302). Pettit, por sua vez, afirmará a concepção republicana de liberdade como um ideal comunitário, uma vez que a escolha dos indivíduos será sempre afetada pelo respeito mútuo requerido pelo ideal de liberdade como não dominação. Apesar disto, também afirmará, assim como os liberais, que o Estado republicano é neutro do ponto de vista dos valores ao não se vincular a nenhuma concepção de bem (Pettit, 1999, p. 162).

A partir desta reflexão poderíamos reconsiderar a questão da caracterização da tradição liberal e de sua diferenciação em relação à tradição republicana. Como se sabe, a origem do liberalismo 
pode ser associada aos embates políticos da revolução inglesa do século XVII, a partir dos quais foram pensados novos princípios de justificação da soberania e dos lugares da política e da religião num contexto de afirmação dos direitos naturais e da emergência dos interesses mercantis e de propriedade. Neste contexto, a doutrina liberal que alcança o centro do sistema político ao derrotar variantes de correntes conservadoras, democráticas radicais e republicanas, já trabalhava em rompimento com a longa tradição do humanismo cívico de concepção da liberdade. Este empreendimento, de fato, fez parte do esforço teórico de Hobbes em seu debate público contra os neorrepublicanos ingleses de seu tempo. Deste ponto de vista, diferentemente do que a crítica liberal afirmaria, Skinner estaria correto ao associar a origem da concepção liberal da liberdade em Hobbes, uma vez que este inauguraria o rompimento com o humanismo cívico do ponto de vista daquilo que Taylor designaria como uma concepção "atomista" da sociedade amplamente desenvolvida pelo liberalismo posterior. ${ }^{13}$ No liberalismo de Locke, este rompimento se faria não apenas em relação ao conceito de liberdade, mas em relação à própria gramática, ou seja, à forma como o liberalismo articularia a partir daí uma determinada concepção da relação entre as dimensões pública e privada da vida. Da concepção da liberdade republicana é retirada sua evocação do ser humano como autocriação, retraduzida para uma visão de mundo já em estreita relação com a visão de mundo iluminista, materialista e mecanicista que faz dos desejos humanos e suas pulsões a expressão mais direta de sua realidade. Neste sentido, o conceito de liberdade é pensado em associação com a realização destes desejos, sem relação com a condição pública da liberdade ou estabelecendo com esta dimensão uma relação instrumental. A questão da liberdade passaria a ser pensada a partir da dimensão privada da vida em rompimento com a cultura do humanismo cívico, inversão expressa no pensamento político de Locke pela afirmação da lógica dos direitos naturais

13 De maneira geral, Taylor (2000) designa como concepção "atomista" da sociedade aquela concepção liberal analítica e normativa que concebe as instituições políticas e a própria vida pública em função da irrealidade da descrição do indivíduo e seus direitos negativos como base dos laços sociais. 
e, em particular, do direito à propriedade como elemento fundamental de compreensão da relação do indivíduo com outros e com seu próprio corpo.

É esta gramática liberal, formada, portanto, em rompimento com o humanismo cívico e reorientando a reflexão sobre a liberdade a partir do campo do mundo privado dos indivíduos e de seus interesses reconhecidos como ontologicamente precedentes à própria comunidade política, que constitui a identidade do liberalismo em sua pluralidade. Ao pensar o mundo político fundamentalmente como instrumento de garantia de uma liberdade que lhe é externa e anterior, o liberalismo erigiu uma gramática da liberdade centrada no mundo privado, delimitando e organizando o mundo público em função de suas necessidades e interesses. Desta forma, se em Locke a origem da liberdade é localizada em direitos pré-políticos que devem ser assegurados pelo contrato posterior que funda o Estado, a economia política traduziria esta gramática na fundamentação da lógica do mercado capitalista como o espaço de exercício da liberdade do indivíduo. O utilitarismo reafirmaria esta concepção ao pensar a liberdade vinculada à expansão dos interesses dos indivíduos e delimitando o campo de legitimidade da intervenção do Estado. Como consequência, a organização política, as leis e a opinião pública poderiam ser repensadas como ameaça à plena expansão da liberdade e não como fundamentos da liberdade em si mesmos.

Do nosso ponto de vista, portanto, esta seria uma forma de responder àquele primeiro conjunto de críticas ao neorrepublicanismo contemporâneo. Reconhecendo a pluralidade da tradição liberal, trata-se de apontar esta gramática que estabelece o mundo privado como lugar privilegiado da liberdade como princípio de unidade do liberalismo em suas várias vertentes. Neste sentido, diferentes e ricas versões do liberalismo ético, igualitário e democrático seriam aquelas que aceitaram pensar o conceito de liberdade, relacionando-o a princípios de justiça, participação e direitos, mesmo ainda inseridos numa gramática que explica a origem da liberdade no mundo privado e na sua salvaguarda. Estas correntes 
foram aquelas que aceitaram ampliar os limites de intervenção legítima do Estado e das leis na consolidação de direitos como forma de contornar assimetrias sociais, mas mantendo uma concepção instrumental do espaço público. Por outro lado, aquelas correntes liberais mais conservadoras caminharam na direção inversa ao acentuarem o discurso privado da liberdade e ao deslegitimarem a intervenção da lei e do Estado como garantidores do sentido público mesmo de liberdade.

No sentido inverso ao da tradição liberal, o republicanismo deveria ser pensado a partir de uma gramática política que aponta a dimensão pública como lugar de origem e fundamento da própria liberdade. Aqui, o lugar da liberdade não é o do indivíduo e de seus interesses e nem a comunidade política poderia ser definida como construção puramente artificial contra o qual se afirmam os direitos. A dimensão ético-político republicana articularia os domínios da vida pública e privada pela afirmação da própria dignidade do mundo público e de sua lógica na regulação das assimetrias do mundo privado. É a partir desta outra forma de conceber a articulação entre as dimensões do público e do privado, refletida não mais a partir da ideia de uma precedência ontológica desta última, mas do reconhecimento do primeiro como fundamento e gênese da vida coletiva, é que se poderia repensar a liberdade em termos republicanos.

Resta-nos a segunda crítica liberal ao neorrepublicanismo contemporâneo, ou seja, a de que o republicanismo não constituiria uma tradição de pensamento político alternativo ao liberal, uma vez que ambos apostam na neutralidade do Estado e na instrumentalidade das virtudes públicas. Neste aspecto, acompanhamos a posição daqueles que apontam a insuficiência do republicanismo de Pettit em responder à crítica liberal, afirmando, para tanto, uma maior proximidade entre a concepção republicana de liberdade e a concepção de liberdade positiva do comunitarismo do que aquela que o próprio Pettit normalmente reconheceria (Spitz, 1995b, Maynor, 2002). Neste sentido, a liberdade republicana deveria ser pensada não apenas como uma outra concepção instrumental, mas 
também como uma forma de compreensão da liberdade política que reconhece certos valores e certas instituições como intrínsecas e constitutivas de um tipo distintivo de tradição política. Em termos mais amplos, trata-se de reafirmar o caráter instituinte da dimensão do político a partir do qual o conceito de liberdade não pode ser compreendido como neutro nem passível de se compor indiferentemente com outras gramáticas que reclamam diferentes concepções de justiça e organizações do Estado em sua relação com a sociedade civil. Neste sentido, trata-se de reconhecer uma maior proximidade do republicanismo neorromano com as formas do republicanismo comunitarista.

A chamada crítica comunitarista explorou a ideia de que o liberalismo político excluiria de sua concepção de sociedade bem ordenada a hipótese segundo a qual a perseguição de fins comuns seja essencial à qualidade de agente moral do sujeito, ou seja, de que o sujeito seja engajado em valores comunitários de tal forma que seja impossível compreendê-lo sem fazer referência a eles. Neste sentido, a tese liberal interditaria toda uma compreensão intersubjetiva do "eu" que só poderia ser definido, em parte, por compartilhar com outras certas aspirações (Sandel, 1984, p. 87; Spitz, 1995b, p. 10). ${ }^{14}$

A tradição republicana neorromana, por sua vez, poderia ser compreendida, por um lado, como próxima do liberalismo ao compreender um ideal de liberdade negativa e de autonomia e ao não supor que a natureza ou algum tipo de teleologia imponha uma única finalidade aos indivíduos como fundamento de uma específica concepção da vida boa. Por outro lado, podemos aproximar o republicanismo de versões comunitaristas na medida em que a liberdade do indivíduo estaria intrinsecamente associada à dos outros cidadãos que compõe sua comunidade política. A república não é somente um instrumento político de organização da compatibilidade dos fins individuais, mas também de interrogação sobre sua validade na medida em que elas podem ser consideradas

14 Em relação a este tipo de crítica ao liberalismo político, ver especialmente Sandel (1984). 
legítimas. Desta forma, o republicanismo teria mais dificuldade em aceitar a dissociação entre o justo e o bem uma vez que, em consonância com o comunitarismo, a adesão de um indivíduo aos fins de sua comunidade é essencial à sua própria identidade enquanto ser livre. Para além do que afirma o republicanismo de Pettit, que concebe a liberdade política puramente como um meio para garantir a liberdade civil, o republicanismo deveria reconhecer a vida política mesma como realidade da liberdade que não pode existir sem instituições justas que requerem uma participação ativa dos cidadãos no estabelecimento de um sistema de direitos recíprocos (Spitz, 1995b, p. 16).

Desta forma, se para Rawls as virtudes políticas não podem ser defendidas e apresentadas com referência a uma determinada concepção do bem, o mesmo não se poderia afirmar em relação ao republicanismo, uma vez que valores e virtudes que acompanham o ideal de liberdade como não-dominação possuem um valor intrínseco e promovem o cultivo de um tipo de cidadão, interferindo, portanto, em suas escolhas individuais. Na perspectiva republicana, no entanto, como esta interferência não é arbitrária, mas visa promover a liberdade como não dominação entre os indivíduos de uma comunidade, ela não poderia ser vista como restrição da liberdade de escolha individual. Como afirma Maynor (2002), as instituições republicanas devem interferir visando à promoção de um senso de proteção do cidadão contra interferências arbitrárias além da promoção de condições de equidade social próprias ao pleno desenvolvimento da cidadania. De fato, se a liberdade republicana pode ser relacionada a ausência de condições de dominação, isto significa que os indivíduos devem estar livres para buscar seus próprios interesses, mas também devem levar em consideração em que medida suas ações afetam as condições de liberdade de outros indivíduos. Neste sentido, a possibilidade de escolha dos indivíduos será sempre afetada pela necessária civilidade e respeito mútuo requeridos pela liberdade como não dominação 
(Maynor, 2002, p. 80). ${ }^{15}$ Diferentemente da concepção do Estado neutro liberal, o Estado republicano deve atuar abertamente em favor do desenvolvimento de formas substantivas de virtude cívica e de uma linguagem comum de cidadania que prepare os cidadãos para exercer um papel ativo em defesa da liberdade. Numa situação em que os indivíduos devem agir levando em consideração outros interesses e buscando não interferir arbitrariamente nas escolhas de outros indivíduos, torna-se de fundamental importância a demanda por direitos de reciprocidade entre os cidadãos de tal modo que eles sejam capazes de estabelecer suas relações e suas escolhas em conformidade com o ideal de não dominação. Por isto mesmo, como aponta Maynor (2002, p. 81), do ponto de vista republicano, as virtudes não podem ser compreendidas de forma meramente instrumental, uma vez que elas são decisivas na formação dos indivíduos para que eles possam desempenhar um papel ativo, tanto na manutenção de sua própria liberdade quanto na sua responsabilidade pela não dominação de outros.

Este é, portanto, um elemento distintivo entre o pensamento republicano e liberal. Os liberais podem admitir que algumas escolhas individuais possam ser influenciadas por virtudes liberais, mas isto não é objetivo do Estado liberal que encara tais virtudes do ponto de vista instrumental. Mantém-se, portanto, a concepção de neutralidade do Estado. A concepção republicana viola esta concepção de neutralidade, já que o poder recíproco de não dominação constitui algo a ser promovido pelo Estado através de versões participativas de cidadania e virtude pública. Por meio do poder de reciprocidade, o caráter do agente é modificado e educado a viver numa situação de não dominação. Desta forma, o Estado republicano procura educar os indivíduos, seus próprios fins são

15 Para além do apontado por Silva (2008), portanto, a questão colocada por Maynor contra Pettit não se restringe ao fato de que este último não perceberia a maior proximidade de sua teoria da liberdade com a das versões comunitaristas. Maynor aponta algo mais substantivo, ou seja, a incompletude da própria teorização de Pettit para aprofundar a concepção de liberdade como não dominação em oposição ao liberalismo. 
construídos para que possam compartilhar de uma vida com base no ideal de não dominação ${ }^{16}$. Por isto mesmo, as virtudes associadas a não dominação e ao poder recíproco têm um valor intrínseco à liberdade republicana e não poderiam ser encaradas como elementos meramente instrumentais.

\section{Conclusão}

Neste artigo, procuramos avaliar os avanços da teoria neorrepublicana da liberdade em dois de seus principais teóricos, Skinner e Pettit, confrontados com duas críticas liberais contemporâneas a este empreendimento de resgate da tradição política republicana. Tais críticas seriam as de que, em primeiro lugar, o neorrepublicanismo de Skinner e Pettit teria falhado na sua caracterização da tradição liberal ao confrontá-la com o republicanismo ao não compreender a pluralidade do liberalismo e ao não levar em consideração dimensões normativas constitutivas desta tradição. Em segundo lugar, a crítica liberal interditaria o projeto neorrepublicano ao afirmar sua compatibilidade com o liberalismo uma vez que ambos seriam partidários de uma concepção instrumental das virtudes públicas e da neutralidade do Estado.

Neste trabalho, defendemos a ideia de que estas criticas liberais se assentam nas insuficiências do neorrepublicanismo de Skinner e Pettit. Neste sentido, para escapar ao bloqueio liberal de suas razões, o neorrepublicanismo deveria elaborar seu conceito de liberdade articulado com uma "gramática" republicana através da qual a relação entre as esferas pública e privada fossem pensadas analítica e normativamente a partir da primeira. Como consequência, o neorrepublicanismo não poderia aceitar, como o liberalismo, uma concepção meramente instrumental das virtudes públicas e da neutralidade do Estado uma vez que, em consonância com

16 Nesta linha argumentativa, interessantes considerações sobre o papel da educação como promotor do desenvolvimento das capacidades (capabilities) requeridas para o florescimento da liberdade em um ambiente social de não dominação podem ser encontradas em Hinchliffe (2015) e Snir, Eylon (2016). 
o conceito de liberdade como não dominação, o Estado deveria fomentar direitos de reciprocidade.

Desta maneira, se o neorrepublicanismo aparece como um campo de possibilidades teóricas para repensar a vida política de nossas sociedades contemporâneas, é certo também que ele se apresenta também como um campo marcado por tensões e lacunas por serem resolvidas.

\section{Referências}

ARENDT, Hannah (1998). Sobre a violência. Brasília: Editora da UnB.

(2008). A Condição Humana. Rio de Janeiro: Forense Universitária.

BERLIN, Isaiah (2002). "Dois conceitos de liberdade”. In: HARDY, H.; HAUSHEER, R. (orgs.). Isaiah Berlin: estudos sobre a humanidade. São Paulo: Companhia das Letras.

BIGNOTTO, Newton (2004). "Problemas atuais da teoria republicana”. In: CARDOSO, S. Retorno ao Republicanismo. Belo Horizonte: Ed. da UFMG.

BUTTLE, Nicholas (2001). "Republican Constitutionalism: a roman ideal". The Journal of political Philosophy v. 9, n. 3, p. 331-349.

COSER, Ivo (2014). “The Concept of Liberty: the polemic between the Neo-Republicans and Isaiah Berlin", Brazilian Political Science Review, v. 8, n. 3.

GRAY, John (2000). Isaiah Berlin. Rio de Janeiro: Difel.

HINCHLIFFE, Geoffrey (2015). Liberty and Education: A Civic Republican Approach. Abingdon: Routledge.

HONOHAN, Iseult (2000). Civic Republicanism. New York: Routledge.

KYMLICKA, Will. (1998) "Liberal Egalitarianism and Civic Republicanism: Friends or Enemies?". In: ALLEN, A.; REGAN, M. (orgs.). Debating Democracy's Discontent. Oxford: Oxford University.

LARMORE, Charles (1999). "The Moral Basis of Political Liberalism", The Journal of Philosophy, v. 96, n. 12, p. 599-621. 
(2001). "A critique of Philip Pettit's republicanism".

Philosophical Issues, v. 11, p. 229-243.

(2003). "Liberal and republican conceptions of

Freedom". Critical Review of International Social \& Political Philosophy, v. 6, n. 1, p. 96-119.

LEFORT, Claude. Pensando o político: ensaios sobre democracia, revolução e liberdade. Rio de Janeiro: Paz e Terra, 1991.

MAYNOR, John (2002). "Another instrumental republican approach?". European Journal of Poltical Theory, v. 1, n. 1, p. 71-89.

MCCORMICK, John (2003). "Machiavelli against republicanism: On the Cambridge School's "Guicciardinian Moments" ". Political Theory, v. 31, n. 5, p. 615-643.

MITCHELL, Annie (2004). "A Liberal Republican "Cato"'. American Journal of Political Science, v. 48, n. 3, p. 588-603.

PALONEN, Kari (1998). "Liberty is too precious a concept to be left to the Liberals". Finish Yearbook of Political Thought, n. 2, p. 243-260.

PATTEN, Allen (1996). "The republican critique of liberalism". British Journal of Poltical Science, v. 26, n.1, p. 25-44.

PETTIT, Philip (1997). Republicanism: a theory of freedom and government. Oxford: Oxford University Press.

(1998). "Reworking Sandel's Republicanism". The Journal of Philosophy, v. 95, n. 2, p. 73-96.

(1999). Republicanismo: una teoria sobre la libertad y el gobierno. Barcelona: Paidos.

(2002). "Keeping Republican Freedom Simple". Political Theory, v. 30, n. 3, p. 339-356.

(2007). Teoria da Liberdade. Belo Horizonte: Del Rey.

POCOCK, John (1975). The Macchavellian Moment: Florentine Political Thought and the Atlantic Republican Tradition. Princeton: Princeton University Press.

RAWLS, John (2000). O Liberalismo Político. Rio de Janeiro: Ática. ROSANVALLON, Pierre (2010). Por uma história do político. São Paulo: Alameda. 
ROGERS, Melvin (2008). "Republican confusion and liberal clarification”. Philosophy and Social Criticism, v. 34, n. 7, p. 799-824.

SANDEL, Michael (1984). "The Procedural Republic and Unencumbered Self”. Political Theory, v. 12, n. 1, p. 81-96.

SILVA, Ricardo (2008). "Liberdade e lei no neorepublicanismo de Skinner e Pettit”. Lua Nova, n. 74, p. 151-194.

SKINNER, Quentin (1991). "The republican ideal of political liberty”. In: BOCK, G (ed.). Machiavelli and Republicanism. Cambridge: Cambridge University Press.

(1999). A liberdade antes do liberalismo. São Paulo: Ed.

Unesp.

(2006). "Rethinking Political Liberty". History Workshop Journal, v. 61, n. 1, p. 156-170.

(2007). "La teoria evolutiva de la libertad de Thomas Hobbes". Revista de Estudios Políticos, n. 134, p. 35-69.

2010. . Hobbes e a liberdade republicana. São Paulo: Ed. Unesp,

SNYR, Itay; EYLON, Yuval (2016). "Pedagogy of non-domination:

Neo-republican political theory and critical education". Policy Futures in Education, v. 14, n. 6, p. 759-774.

SPITZ, Jean-Fabien (1995a). La Liberté Politique. Paris: PUF, 1995a. (1995b). "Le Republicanisme: une troisième voie entre libèralisme et communautarisme?". Le Banquet, n. 7, p. 1-17. TAYLOR, Charles (2000). "Propósitos entrelaçados: o debate liberal comunitário”. In: Argumentos Filosóficos. São Paulo: Loyola. WALDRON, Jeremy (1987). "Theoretical Foundations of Liberalism", Philosophycal Quarterly, v. 37, n. 147, p. 127-150.

\section{Resumo}

Neste artigo destacamos duas das críticas liberais feitas a teoria da liberdade neorrepublicana de Skinner e Pettit. Pretendemos sustentar que, embora estes autores tenham contribuído decisivamente ao procurar atribuir estatuto próprio à liberdade republicana, ainda resta insuficiente a análise de elementos que podem tornar a concepção republicana 
de liberdade mais claramente alternativa à liberal. Faltaria uma análise da liberdade republicana associada à uma "gramática" republicana, no sentido de que pensariam a liberdade desarticulada de uma linguagem de direitos e deveres que configuram ás relações entre público e privado a partir da lógica do próprio lugar do "político". Além disto, seria bastante problemático o recurso de tomar certas virtudes e ideais da vida pública de maneira puramente instrumental, sem reconhecer que certos valores têm importância intrínseca à liberdade republicana. Retomar estas questões seriam fundamentais para repensar o próprio sentido da liberdade republicana.

Palavras-chave: Republicanismo, Liberalismo, Liberdade, Política

\section{Abstract}

In this paper we highlight two of the liberal critiques made of Skinner and Pettit's neo-republican theory of liberty. We intend to argue that, although these authors contributed decisively in seeking to attribute their own status to republican liberty, the analysis of elements that can make the republican conception of freedom more clearly alternative to liberal still remains insufficient. It would lack an analysis of republican freedom associated with a republican "grammar", in the sense that they would think the unrestrained freedom of a language of rights and duties that configure the relations between public and private from the logic of the place of the "political." Moreover, it would be quite problematic to use certain virtues and ideals of public life in a purely instrumental way, without recognizing that certain values are intrinsically important to republican freedom. To retake these questions would be fundamental to rethink the very meaning of republican freedom.

Keywords: Republicanism, Liberalism, Freedom, Politics

Recebido em 27 de fevereiro de 2018

Aprovado em 26 de agosto de 2019 